\title{
BMJ Open Prevalence of and factors associated with adopting bone health promoting behaviours among people with osteoporosis in Taiwan: a cross- sectional study
}

Po-Han Chen, ${ }^{1}$ Ming-Shyan Lin, ${ }^{2}$ Tung-Jung Huang,,${ }^{3,4}$ Mei-Yen Chen ${ }^{2,5,6}$

To cite: Chen P-H, Lin M-S, Huang T-J, et al. Prevalence of and factors associated with adopting bone health promoting behaviours among people with osteoporosis in Taiwan: a crosssectional study. BMJ Open 2017;7:e015980. doi:10.1136/ bmjopen-2017-015980

- Prepublication history for this paper is available online. To view these files, please visit the journal online (http://dx.doi org/10.1136/bmjopen-2017015980).

P-HC and M-SL contributed equally.

Received 18 January 2017

Revised 26 June 2017

Accepted 3 August 2017

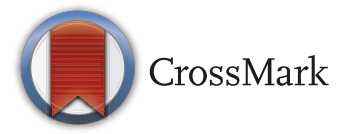

${ }^{1}$ Department of Orthopedic Surgery, Chang Gung Memorial Hospital, Yunlin, Taiwan

${ }^{2}$ Department of Cardiology, Chang Gung Memorial Hospital, Yunlin, Taiwan

${ }^{3}$ Department of Chest, Chang Gung Memorial Hospital, Yunlin, Taiwan

${ }^{4}$ Department of Respiratory Care, Chang Gung University of Science and Technology, Chiayi, Taiwan

${ }^{5}$ Department of Nursing, Chang Gung University, Taoyuan,

Taiwan

${ }^{6}$ Department of Nursing, Chang Gung University of Science and Technology, Chiayi, Taiwan

Correspondence to

Dr Mei-Yen Chen;

meiyen@mail.cgust.edu.tw

\section{ABSTRACT}

Objectives To detect osteopenia, osteoporosis, treatments received and bone health promoting behaviours early among postmenopausal women and elderly men, and to explore the associated factors.

Design A community-based cross-sectional study. Settings Two rural townships in Yunlin County, Taiwan. Participants A total of 941 adults including 651 postmenopausal women and 290 elderly men aged $>65$ years.

Outcome measures Bone mineral density was measured using dual-energy $X$-ray absorptiometry. Adults with a T-score $<-1.0$ for bone mineral density were classified as having osteopenia, and those with a T-score $<-2.5$ as having osteoporosis. The main outcome measures were prevalence of osteopenia, osteoporosis, receiving medication and bone health promoting behaviours. A logistic regression model was used to analyse the factors associated with adopting bone health promoting behaviours.

Results Across both genders, $63.7 \%$ of participants were identified as having osteopenia (46.9\%) or osteoporosis (16.8\%). A high proportion of participants reported never or seldom performing regular exercise, or having sunlight exposure, a diet containing calcium/vitamin D or taking medications/supplements for bone health. Although $34.8 \%$ reported taking supplements, $92.4 \%$ were inadequate. The logistic regression model indicated that older age (OR 1.03 $95 \% \mathrm{Cl} 1.01$ to $1.05, \mathrm{p}=0.006$ ) and a high education level (OR $1.07,95 \% \mathrm{Cl} 1.03$ to $1.11, \mathrm{p}<0.001$ ) were significant factors associated with bone health promoting behaviours. Conclusion The prevalence of osteopenia and osteoporosis among postmenopausal women and elderly men is worryingly high and most of them receive inadequate treatment and perform few bone health promoting behaviours. Interventions are therefore urgently required to address the right methods for delaying osteoporosis among postmenopausal women and elderly men in rural areas.

\section{INTRODUCTION}

Osteoporosis is a disease characterised by low bone mass and structural deterioration of bone tissue, leading to bone fragility and an increased susceptibility to fractures. ${ }^{1}$
Strengths and limitations of this study

- This study involved a large number of participants in rural areas who received dual-energy X-ray absorptiometry and completed a bone health promoting behaviours questionnaire.

- Few studies have explored the prevalence of receiving adequate treatment and of bone health promoting behaviours among postmenopausal women and elderly men with osteoporosis in rural areas.

- Recall bias should be taken into consideration as participants had different durations of menopause and osteoporosis, and other health conditions were not controlled.

- Participants were recruited by non-random sampling and from only one county, which limited the generalisability of the study findings.

Osteoporosis is a major cause of fractures and ranks high among diseases that cause people to become bedridden with serious complications. ${ }^{12}$ These complications may be life-threatening in elderly people. ${ }^{3}$ Fractures of the hip incur the greatest morbidity and mortality, and give rise to the highest direct costs for health services. According to the world statistics, 1.7 million hip fractures occurred worldwide in 1990; this figure is expected to rise to 6 million in $2050 .^{1}$ Hip fracture rates in Taiwan are among the highest in the world. ${ }^{4}$ A number of research studies have shown that older age, the female gender, social deprivation and low education are the main factors associated with osteoporosis. ${ }^{15}$ However, few studies have measured bone mineral density using dual-energy X-ray absorptiometry through a community health promotion programme for the early detection of osteoporosis among postmenopausal women and elderly men. 
Evidence indicates that many antiosteoporosis treatments, such as antiresorptive drugs, the selective oestrogen receptor modulator and anabolic drugs, which decrease the risk of osteoporotic fracture by slowing bone resorption and turnover and maintaining or increasing bone mass, ${ }^{67}$ and specific bone mass health promoting behaviours (eg, a diet containing calcium or exercise) can reverse or maintain bone mass. ${ }^{189}$ However, most of the previous studies focused on the prevalence, cost or burden of osteoporosis in many developed countries ${ }^{2}{ }^{10}{ }^{11}$; few studies focused on the adoption of treatment and bone mass health promoting behaviours among adults with osteoporosis. As primary healthcare providers are expected to initiate health promotion programmes in various settings, understanding the prevalence of the adoption of the right treatments and of bone mass health promoting behaviours among postmenopausal women and elderly men plays an important role in the early detection of osteoporosis.

In addition to age and the female gender being the main factors associated with osteoporosis, other risk factors for osteoporosis and hip fracture include early menopause, low bone mineral density, low body mass index, obesity, previous fragility fractures, hip fracture in the parents, hip geometry, genetic factors and lifestyle factors. ${ }^{2} 1213$ Furthermore, calcium and vitamin $\mathrm{D}$ intake are positively correlated with bone mineral accretion/bone density and a decrease in bone mass loss. Regular exercise contributes to the development of high peak bone mass and may reduce the risk of falls in older persons, especially resistance and high-impact activities or low to moderate intensity weight-bearing exercise. ${ }^{2}$ Exposure to sunlight for $5-15 \mathrm{~min}$, two to three times per week, has health benefits dependently and independently of vitamin D synthesis. ${ }^{14} 15$ Maintaining adequate bone mass and muscle mass prevents osteoporosis. ${ }^{216}$ Regarding smoking and alcohol, they are harmful in terms of bone density and bone fracture. $^{12} 17$

In recent decades, most people are able to live longer than 80 years in many countries, and a slow decrease in bone mass is a normal ageing process. As such, how to maintain bone mass is an important factor when conducting health promotion programmes for the ageing population. To the best of our knowledge, very few studies have examined the adoption of daily behaviours related to bone mass health promoting behaviours among people who were identified as having osteopenia or osteoporosis. From the perspective of prevention, bone health promotion studies in rural areas have been scarce. ${ }^{5}$ Therefore, the aim of this study was to estimate the prevalence of osteopenia, osteoporosis, receiving the right treatment and adopting bone mass health promoting behaviours among postmenopausal women and elderly men, and to explore the associated factors in the high proportion of the ageing population in rural areas.

\section{METHODS}

\section{Design, sample and setting}

This was a community-based cross-sectional study involving postmenopausal women and elderly men living in a western coastal region in Yunlin County, Taiwan. Community-based health screening was conducted in collaboration with an orthopaedic clinic in a local hospital between October 2015 and July 2016. Participants were selected using convenience sampling. The inclusion criteria were (1) postmenopausal women $\geq 40$ years old who were identified by the research team's physician with the consideration that the criticality of osteoporosis in women would be greater than in men; in addition, a few women $<50$ years old suffer from advanced menopause due to disease; (2) men $\geq 65$ years old according to their date of birth; (3) the ability to complete questionnaires in a Mandarin or Taiwanese dialect via a face-to-face interview and (4) agreement to participate in the study and provision of informed consent prior to participation. The exclusion criteria included (1) inability to complete the questionnaires, (2) inability to walk independently and (3) serious learning difficulties, such as dementia and stroke.

\section{Measurements}

1. Bone mineral density was measured in the lumbar spine, femoral neck and whole femur using dual-energy X-ray absorptiometry in collaboration with the local hospital, and was interpreted by a senior radiologist. According to universal criteria $^{1}$ and the recommendation by the HPA, ${ }^{2}$ adults who have a T-score $<-1.0$ for bone mineral density were classified as having osteopenia, and those with a T-score $<-2.5$ were classified as having osteoporosis.

2. Cardiometabolic risk factors and metabolic syndrome were measured in terms of the presence of the following abnormal biomarkers that were based on the national standard of the Ministry of Health and Welfare: ${ }^{18}(1)$ fasting blood glucose (FBG) level $>100 \mathrm{mg} / \mathrm{dL}$, (2) triglyceride (TG) level $>150 \mathrm{mg} / \mathrm{dL}$, (3) high-density lipoprotein cholesterol (HDL-C) level $<40 \mathrm{mg} / \mathrm{dL}$ for men or $50 \mathrm{mg} / \mathrm{dL}$ for women, (4) systolic/diastolic blood pressure of $>130 / 85 \mathrm{~mm} \mathrm{Hg}$ and (5) waist circumference $>90 \mathrm{~cm}$ for men and $80 \mathrm{~cm}$ for women. Blood samples were drawn after an 8-hour fast, and serum biomarkers were measured enzymatically at the central laboratory at the cooperating hospital. Metabolic syndrome was defined as three or more abnormal measures of the five biomarkers. ${ }^{18}$

3. Bone health promoting behaviours were based on those reported in the literature, ${ }^{2819}$ which assess the following four dimensions. First, physical activity level was determined according to whether a participant regularly (usually/always) exercises for $>30 \mathrm{~min}$ per day, for $150 \mathrm{~min}$ per week and for $>3$ days or irregularly (seldom/never) engages in physical activity and for $\leq 3$ days. Second, sun exposure was measured by asking the participant "How often do you go out and let 
your hands, face, and arms be exposed to the sun for 10 min at least 3 times per week?" Their exposure was classified as regular (usually/always) if they responded greater than two times per week and as irregular (seldom or never) if they responded less than or equal to two times per week. Third, whether their diet contained calcium and vitamin $\mathrm{D}$ was determined by the question, "How often do you consume food that is rich in calcium or vitamin D (eg, meat, milk, fish, cheese, beans, and dark-colored vegetables) each day?" The response was classified as regular (usually/ always) if they answered $>3$ days per week or irregular (seldom or never) if they answered less than or equal to three times per week. Fourth, medication or supplements for bone health were determined by the question, "Have you taken supplements with calcium or medication prescribed by physicians (eg, anti-osteoclast medications, calcitonin, bisphosphonates, teriparatide, or estrogen-related hormone therapy)?" The response was classified as regular (usually) if they had taken these medications/supplements $>3$ days per week or as irregular (seldom or never) if they had taken these medications/supplements $\leq 3$ days per week.

4. Cigarette smoking and alcohol drinking were classified as either (1) never having engaged in cigarette or alcohol consumption or (2) currently consume or formerly consumed.

\section{Procedure and ethical considerations}

This study was approved by an institutional review board ethical committee (number 104-9925B) and conducted in accordance with the principles of the Declaration of Helsinki (2008). All research assistants were senior nursing students who underwent 8 hours of training via two training programmes provided by the investigators. The research assistants measured the height, weight, waist circumference and blood pressure of participants, according to standard procedures. Specimen biomarkers were collected by the collaborating hospital with 8 hours of fasting on the same day.

\section{Statistical analysis}

We compared the participants' demographic characteristics among three groups of bone mineral density using the $\mathrm{X}^{2}$ test for categorical variables and the Kruskal-Wallis analysis for continuous variables. We divided participants who adopted bone mass health promoting behaviours into two groups (infrequent $\leq 1 \mathrm{vs}$ frequent $\geq 2$ ) and further compared the demographic characteristics between the groups using the $\mathrm{X}^{2}$ test for categorical variables and the Mann-Whitney $\mathrm{U}$ test for continuous variables. To investigate the factors associated with adopting bone health promoting behaviours, we incorporated the demographic characteristics, being with or without metabolic syndrome and status of bone mineral density into a multivariable logistic regression model. We performed the data analyses using IBM SPSS V.22.

\section{RESULTS}

Of the 1001 participants enrolled, 60 failed to complete the interview and dual-energy X-ray. The majority of the participants were women $(n=651,69.2 \%)$, and the mean age was 66.7 years $(\mathrm{SD}=8.3)$. The most common educational level was primary school $(78.3 \%)$, and most of the participants were overweight $(n=311,33.0 \%)$ or obese $(n=340,36.2 \%)$. More than half of the participants had osteopenia (46.9\%) and osteoporosis (16.8\%). The most frequent metabolic syndrome component was high blood pressure $(66.7 \%)$, followed by abnormal waist circumference (central obesity, 57\%), high FBG level (49.3\%), low HDL-C level (32.7\%), high TG level (20.4\%) and the prevalence rate of metabolic syndrome was $42.3 \%$ (table 1).

Table 1 shows that $64.9 \%(\mathrm{n}=611)$ of the participants reported never or seldom performing exercise, $69.5 \%$ reported insufficient sunlight exposure, $87.2 \%$ reported never or seldom adopting a diet containing calcium/ vitamin $\mathrm{D}$ and $65.2 \%$ reported taking supplements for bone health. Among the remainder, 34.8\% reported taking supplements, but only $7.6 \%$ received the right treatments containing a calcium supplement or physician-prescribed medication; the rest of the supplements were glucosamine-related products or multiple vitamin-related products (eg, Centrum, Ensure). Concerning substance use, $11.5 \%$ reported being current or former smokers and $13.0 \%$ reported alcohol intake.

Table 2 shows that osteopenia and osteoporosis were diagnosed in $43.4 \%$ and $6.9 \%$ of elderly men, respectively, and in $48.4 \%$ and $21.2 \%$ of postmenopausal women, respectively. Among elderly men, those who have a lower body mass index $(\mathrm{p}<0.002)$ and who smoke cigarettes $(p=0.016)$ tended to have osteoporosis. In the female gender, those who had osteoporosis tended to be significantly older $(p<0.001)$, have a lower body mass index $(p<0.001)$, low level of education $(p<0.001)$, more frequently adopted a diet containing calcium $/ \mathrm{D}_{3}$, infrequently consumed alcohol and had fewer cardiometabolic risk factors.

Univariate analysis of the factors associated with adopting bone mass health promoting behaviours by gender indicated that, in both genders, only $27.6 \%$ reported regularly adopting bone mass health promoting behaviours (table 3). Except for the finding that women with a higher education level tended to adopt bone mass health promoting behaviours, there were no differences in gender, age, cardiometabolic factors and the status of bone mineral density. To investigate the factors associated with adopting bone mass health promoting behaviours, the demographic characteristics were incorporated into a multivariable logistic regression model. Table 4 shows that older age (OR 1.03, 95\% CI 1.01 to $1.05, \mathrm{p}=0.006)$ and receiving more years of education (OR 1.07, 95\% CI 1.03 to 1.11 , $\mathrm{p}<0.001$ ) were factors significantly associated with bone mass health promoting behaviours. 
Table 1 Demographic characteristics $(n=941)$

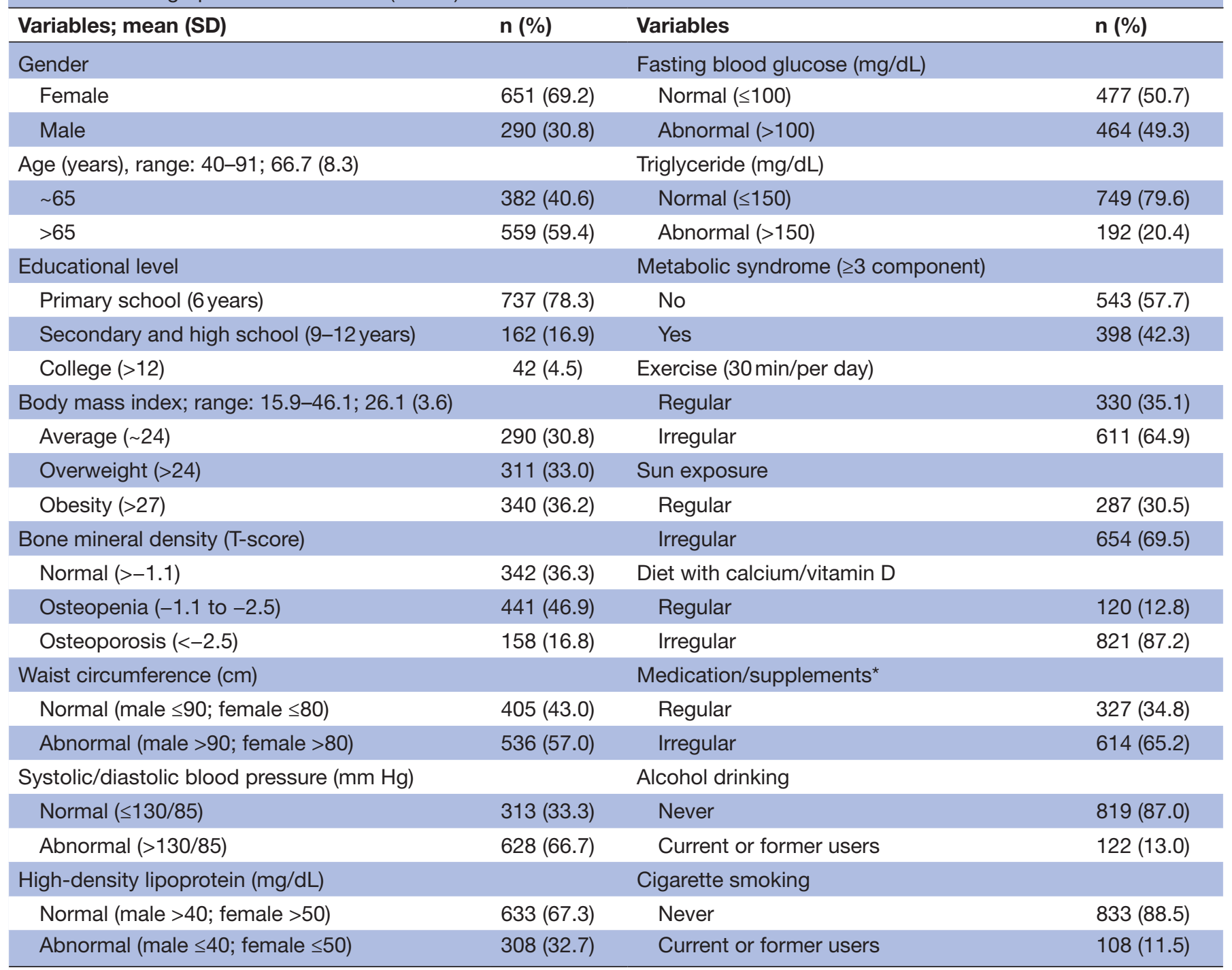

*Medication supplements: $7.6 \%(n=25)$ contain calcium supplement or medication from physician's prescription; $75.5 \%$ ( $n=247)$ used glucosamine-related products or multiple vitamin-related products, for example, Centrum, Ensure, vitamin B group; $16.8 \%$ unknown or Chinese herb $(n=55)$.

\section{DISCUSSION}

Although random sampling was not performed, the current study's analysis of a large rural sample, in which osteoporosis was identified early, provides a useful finding for the development of effective intervention programmes. Two key findings emerged from this study. First, through using dual-energy X-ray absorptiometry, we found a high prevalence of osteopenia and osteoporosis in elderly postmenopausal women; however, their bone mineral density status was not affected by their bone health promoting behaviours. Second, a gap between knowledge and application was found because few people received the right treatment for osteoporosis.

\section{Prevalence of osteoporosis and inadequate treatment}

The present study found that the prevalence rate of osteoporosis was $6.9 \%$ for men over 65 years old and $21.2 \%$ for postmenopausal women. In comparison, the Nutrition and Health Survey in Taiwan ${ }^{2}$ found that the prevalence of femoral neck osteoporosis in individuals aged over 50 years was $10.7 \%$ in men and $12.1 \%$ in women. Why was the prevalence lower in older men and higher in women in our present study than in the national representative study? Is it that most of the rural men have worked hard in the agricultural field? The possible reasons might be due to sample variation, such as age and geography. Further study is necessary to explore the risk factors associated with osteoporosis in different regions, such as rural and urban areas in which people have different lifestyles.

The Taiwanese government launched a national health insurance programme in 1995, which provided more than eight items of free medication (eg, bisphosphonates, calcitonin, teriparatide or oestrogen) to be taken by mouth every day or by intravenous injection every 3 months for postmenopausal women and men at 


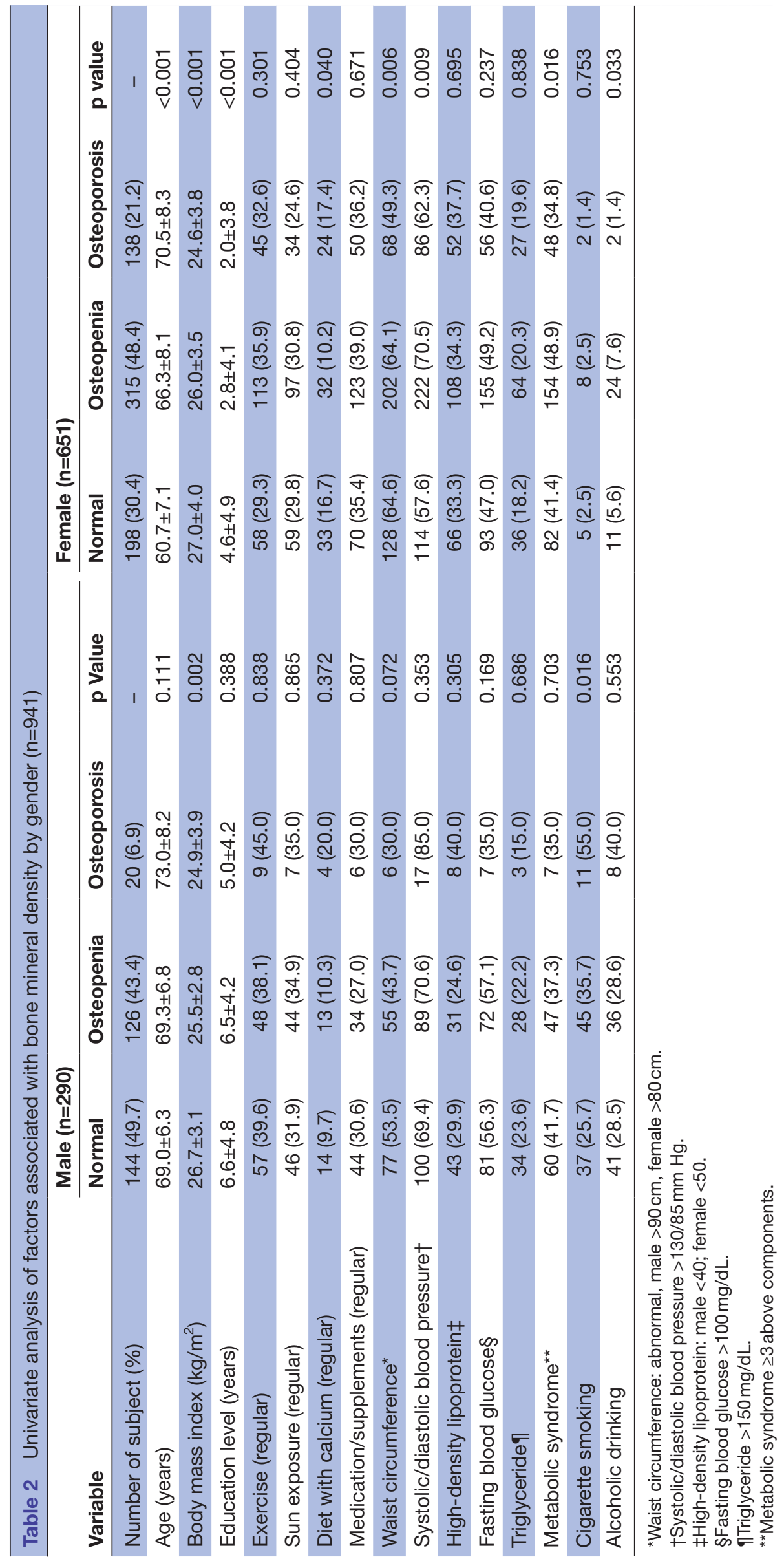




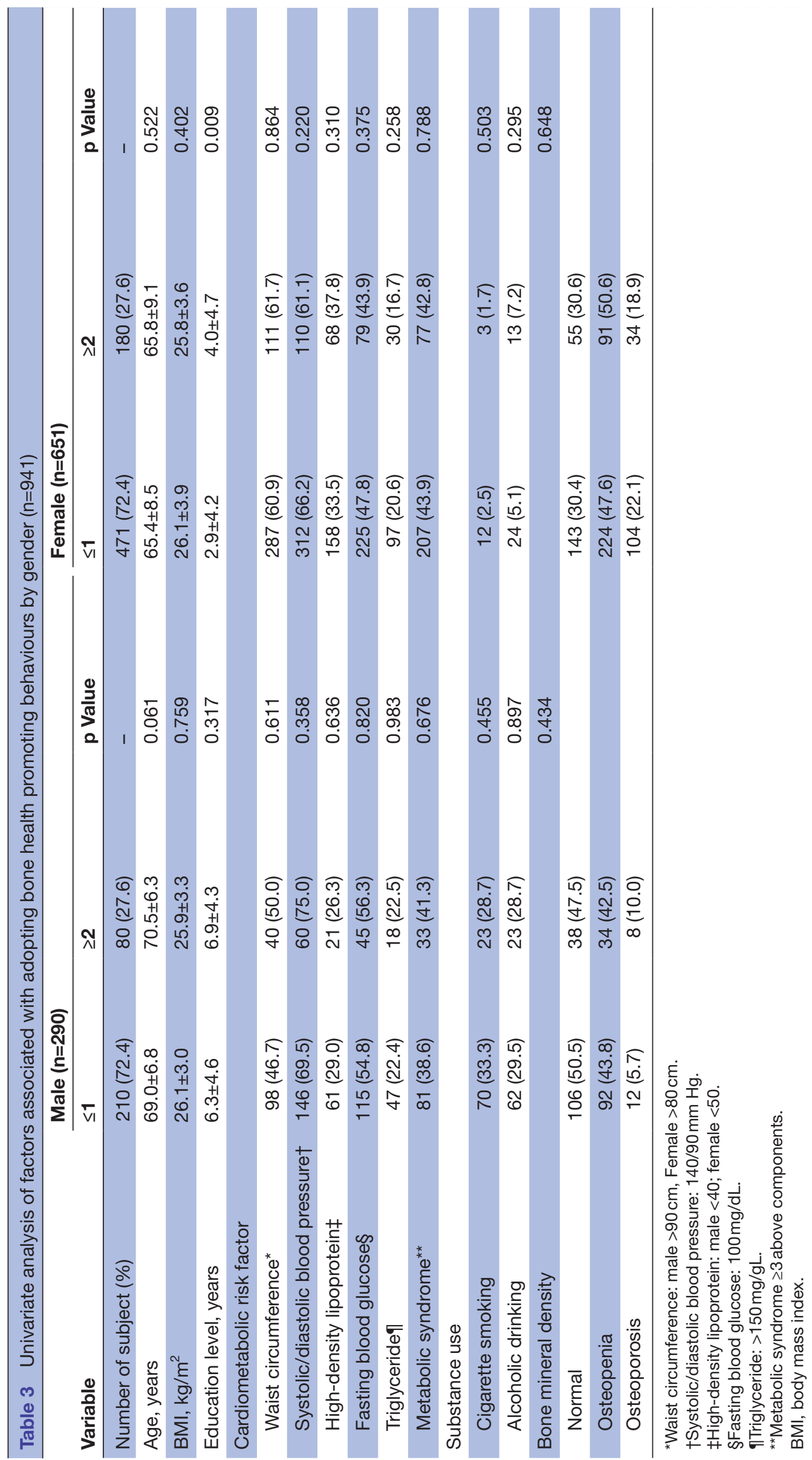


Table 4 Logistic regression analysis of factors associated with adopting bone health promoting behaviours $(n=941)$

\begin{tabular}{|c|c|c|}
\hline Variables & OR $(95 \% \mathrm{Cl})$ & p Value \\
\hline Gender (1=female) & 1.42 (0.94 to 2.16$)$ & 0.100 \\
\hline Age, years & $1.03(1.01$ to 1.05$)$ & 0.006 \\
\hline Body mass index & 0.98 (0.94 to 1.03$)$ & 0.430 \\
\hline Education level, years & $1.07(1.03$ to 1.11$)$ & $<0.001$ \\
\hline Metabolic syndrome (1=yes) & $1.05(0.75$ to 1.46$)$ & 0.793 \\
\hline Cigarette smoking (1=yes) & 0.75 (0.44 to 1.29$)$ & 0.301 \\
\hline Alcoholic drinking (1=yes) & 1.35 (0.84 to 2.16$)$ & 0.214 \\
\hline \multicolumn{3}{|l|}{ Bone mineral density } \\
\hline Normal & Reference & \\
\hline Osteopenia & $1.02(0.73$ to 1.43$)$ & 0.918 \\
\hline Osteoporosis & 0.87 (0.54 to 1.41$)$ & 0.572 \\
\hline
\end{tabular}

high risk of fragility fractures. ${ }^{20}$ Recently, according to the Taiwan National Health Insurance Research Database, Chan et $a l^{21}$ found that persistence and adherence to teriparatide were low in Taiwanese patients with osteoporosis and that greater persistence and adherence were associated with a lower incidence of hip and other non-vertebral fractures. Previous studies have shown that, from 1999 to 2010, there was a decline in hip fracture rates among elderly Taiwanese adults with a concomitant increase in antiosteoporosis medication expenditure. ${ }^{4}$ However, the present study found that only one-third of participants reported that they had used medications or supplements for bone health. Surprisingly, among these, only $7.6 \%$ received the right treatment (eg, a calcium-containing supplement or medication prescribed by a physician). In addition, many supplements were taken according to information gained from watching television and using the Internet or were introduced by relatives. This phenomenon might be due to limited medical resources and inadequate bone health education provided by primary healthcare providers. Enhancing the awareness of bone health promoting programmes is an important issue for rural adults.

\section{Adults with osteoporosis adopted few bone health promoting behaviours}

Previous studies have indicated that the incidence rate of hip fractures has decreased in many developed countries, ${ }^{12} 1922$ which is positively associated with the increase in calcium intake from food and an increase in the consumption of calcium and vitamin D supplements. The present study indicated a high prevalence of adults with osteoporosis who reported never or seldom performing regular exercise, or having sunlight exposure or a diet containing calcium/vitamin D. These findings are similar to those found in some developed countries, such as in France, where only $20 \%$ of women consumed $\geq 1000 \mathrm{mg}$ of calcium per day and the prevalence of vitamin D inadequacy was $>85 \%$ in women with osteoporosis or osteopenia aged over 50 years as well as in elderly subjects over 80 years old. ${ }^{8} 19$

Considering the burden of osteoporosis-related fracture issues and the financial balance of insurance, delaying the osteoporosis process through bone health promotion programmes is an important strategy for rural postmenopausal women and elderly men. Some evidence indicates that ultraviolet radiation is essential to the body as it stimulates the production of vitamin D. ${ }^{15}$ Vitamin $\mathrm{D}$ has an important function in increasing calcium and phosphorus absorption from food and plays a crucial role in skeletal development, immune system function and blood cell formation. ${ }^{15}$ Moreover, few studies and health policies have mentioned this action. Fortunately, Taiwan is located at the $25^{\circ} \mathrm{N}$ latitude, in which most of the four seasons have sunny days. Therefore, theoretically, many adults will have enough sun exposure in their daily life. However, the present study showed that only $30.5 \%$ were regularly exposed to the sun for around $10 \mathrm{~min}$ for three times per week. The possible reasons might be that people avoid sunlight exposure by working inside the house and wrapping themselves up by covering their head and extremities in clothes, especially women. Further studies are necessary to understand the reasons and mechanisms of sun exposure and bone health promoting programmes.

\section{Being overweight tends to protect against osteoporosis}

The present study indicated that, in postmenopausal women, having more cardiometabolic risk factors or metabolic syndrome was negatively associated with osteoporosis. To our knowledge, central obesity, high blood pressure and metabolic syndrome are correlated with many chronic diseases (eg, atherosclerosis, stroke or cardiovascular diseases). Not surprisingly, these results are similar to some previous studies. ${ }^{23-26} \mathrm{~A}$ meta-analysis that assessed the association between metabolic syndrome, risk of fractures and bone mineral density, found that metabolic syndrome was associated with a reduced fracture risk. ${ }^{25}$ In Japan, Yamaguchi et al conducted a correlation study with 214 postmenopausal women (age range: 47-86years, mean 62.7) that showed that abnormal plasma lipids levels (eg, total cholesterol, low-density lipoprotein cholesterol, HDL-C or TG) were significantly and inversely correlated with the absolute values of both radial and distal radial bone mineral density. This phenomenon might be explained by plasma lipids contributing to bone mass, and plasma lipids might be the common factor underlying both osteoporosis and atherosclerosis. However, further studies are needed to explore the paradox between cardiometabolic risk factors and bone mineral density.

Primary healthcare providers are at the forefront of addressing the global osteoporosis and metabolic syndrome pandemic through their role in community health promotion programmes. Without a solid rationale to explain the relationship between being overweight, central obesity, plasma lipids and osteoporosis, we must 
be careful when starting weight loss programmes for postmenopausal women and elderly men. Notably, the present results could be used by healthcare providers when paying attention to general weight reduction; that is, they should also focus on increasing or maintaining muscle mass. Because the paradox between central obesity and osteoporosis in elderly men and postmenopausal women is unknown, a personalised education programme for postmenopausal women with osteoporosis should be developed in further studies, such as translating recommended guidelines for osteoporosis prevention into lay terms that include dietary calcium, vitamin $\mathrm{D}$, the types of physical activity that assist with bone strength and effective medications or treatments.

\section{Limitations}

A key strength of the present study is the discovery of the high prevalence of osteoporosis, the low rate of receiving the right treatment, and few bone health promoting behaviours among postmenopausal women and elderly men in rural areas. However, our study has a number of limitations. First, the non-random sampling and geographical scope, which limits the ability to generalise these findings, could pose a potential threat to internal validity. Second, recall bias should be taken into consideration as participants had different durations of menopause and osteoporosis, and other health conditions were not controlled.

\section{CONCLUSION}

Despite these limitations, the findings revealed a high prevalence of osteopenia and osteoporosis, and the low adoption of treatment and bone health promoting behaviours among postmenopausal women and elderly men in rural areas. Reducing health disparity is an important goal for public and private health agencies in Taiwan. Primary healthcare providers could reduce the consequences of low bone mineral density and enhance the self-management of bone health promoting behaviours through community health promotion programmes.

Acknowledgements We would like to thank all the participants who took part in this study and all staff in the Chang Gung Memorial Hospital, Yunlin branch, for their support in making this study possible.

Contributors $\mathrm{P}-\mathrm{HC}$ and $\mathrm{M}-\mathrm{YC}$ were involved in the conceptualisation of the study, study design, data analysis, development of the discussion section and editing of the final draft for publication. M-SL and T-JH gave valuable contributions to the present study's design and manuscript. All authors read and approved the final manuscript.

Funding The study was supported by a grant from the Taiwan Formosa Plastic Company (FCRPF690011) and Chang Gung Memorial Hospital (BMRP148).

Competing interests None declared.

Patient consent Obtained.

Ethics approval This study was approved by the institutional review board of the ethical committee of Chang Gung Memorial Hospital (IRB 104-9925B).

Provenance and peer review Not commissioned; externally peer reviewed. Data sharing statement No additional data are available.

Open Access This is an Open Access article distributed in accordance with the Creative Commons Attribution Non Commercial (CC BY-NC 4.0) license, which permits others to distribute, remix, adapt, build upon this work non-commercially, and license their derivative works on different terms, provided the original work is properly cited and the use is non-commercial. See: http://creativecommons.org/ licenses/by-nc/4.0/

C Article author(s) (or their employer(s) unless otherwise stated in the text of the article) 2017. All rights reserved. No commercial use is permitted unless otherwise expressly granted.

\section{REFERENCES}

1. World Health Organization, WHO. Chronic diseases and health promotion: Osteoporosis. http://www.who.int/chp/topics/rheumatic/ en/ (accessed 13 Dec 2016).

2. Health Promotion Administration,Ministry of Health and Welfare. Taiwan osteoporosis: practice guideline. http://www.hpa.gov.tw/ BHPNet/Web/HealthTopic/TopicArticle.aspx?No=200712250098\& parentid=200712250018 (accessed 10 Jan 2017).

3. Chou YC, Shih CC, Lin JG, et al. Low back pain associated with sociodemographic factors, lifestyle and osteoporosis: a populationbased study. J Rehabil Med 2013;45:76-80.

4. Chan DC, Lee YS, Wu YJ, , et al. A 12-year ecological study of hip fracture rates among older Taiwanese adults. Calcif Tissue Int 2013;93:397-404.

5. Thorne K, Johansen A, Akbari A, et al. The impact of social deprivation on mortality following hip fracture in England and Wales: a record linkage study. Osteoporos Int 2016;27:2727-37.

6. Inderjeeth CA, Chan K, Kwan K, et al. Time to onset of efficacy in fracture reduction with current anti-osteoporosis treatments. J Bone Miner Metab 2012;30:493-503.

7. Papapoulos SE. Anabolic bone therapies in 2014: New boneforming treatments for osteoporosis. Nat Rev Endocrinol 2015;11:69-70.

8. Dupuy C, Lauwers-Cances V, van Kan GA, et al. Dietary vitamin $D$ intake and muscle mass in older women. Results from a crosssectional analysis of the EPIDOS study. J Nutr Health Aging 2013;17:119-24.

9. Hawley S, Leal J, Delmestri A, et al. Anti-osteoporosis medication prescriptions and incidence of subsequent fracture among primary hip fracture patients in England and Wales: An interrupted timeseries analysis. J Bone Miner Res 2016;31:2008-15.

10. Driessen JH, Hansen L, Eriksen SA, et al. The epidemiology of fractures in Denmark in 2011. Osteoporos Int 2016;27:27.

11. Modi A, Siris ES, Tang J, et al. Cost and consequences of noncompliance with osteoporosis treatment among women initiating therapy. Curr Med Res Opin 2015;31:757-65.

12. Kanis JA, Odén A, McCloskey EV, et al. A systematic review of hip fracture incidence and probability of fracture worldwide. Osteoporos Int 2012;23:2239-56.

13. Tatsuno I, Terano T, Nakamura M, et al. Lifestyle and osteoporosis in middle-aged and elderly women: Chiba bone survey. Endocr $J$ 2013;60:643-50.

14. Hoel DG, Berwick M, de Gruijl FR, et al. The risks and benefits of sun exposure 2016. Dermatoendocrinol 2016;8:e1248325.

15. World Health Organization, WHO. The known health effects of UV. http://www.who.int/uv/faq/uvhealtfac/en/index1.html (accessed 12 Oct 2016).

16. Hosking SM, Dobbins AG, Pasco JA, et al. Knowledge change regarding osteoporosis prevention: translating recommended guidelines into user-friendly messages within a community forum. BMC Res Notes 2015;8:33.

17. Munshi R, Kochhar A, Garg V. Impact of dietary habits and physical activity on bone health among 40 to 60 year old females at risk of osteoporosis in India. Ecol Food Nutr 2015;17:1-23.

18. Health Promotion Administration. Metabolic syndrome. http://www. hpa.gov.tw/English/ClassShow.aspx?No=201609060002 (accessed 23 Dec 2016).

19. Bruyère $\mathrm{O}$, Slomian J, Beaudart $\mathrm{C}$, et al. Prevalence of vitamin D inadequacy in European women aged over 80 years. Arch Gerontol Geriatr 2014;59:78-82.

20. National Health Insurance Administration, Ministry of Health and Welfare, Taiwan ROC. National Health Insurance Annual Report 2014-2015. http://www.hpa.gov.tw/English/file/ContentFile/ 201502140514171717/2014_Health_Promotion_Administration_ Annual_Report.pdf. (accessed 31 Dec 2016).

21. Chan DC, Chang CH, Lim LC, et al. Association between teriparatide treatment persistence and adherence, and fracture incidence in Taiwan: analysis using the National Health Insurance Research Database. Osteoporos Int 2016;27:2855-65. 
22. Ballane G, Cauley JA, Luckey MM, et al. Secular trends in hip fractures worldwide: opposing trends East versus West. J Bone Miner Res 2014;29:1745-55.

23. Rosengren BE, Ahlborg HG, Mellström D, et al. Secular trends in Swedish hip fractures 1987-2002: birth cohort and period effects. Epidemiology 2012;23:623-30.

24. Chang CS, Chang YF, Wang MW, et al. Inverse relationship between central obesity and osteoporosis in osteoporotic drug naive elderly females: The Tianliao Old People (TOP) Study. J Clin Densitom 2013:16:204-11.
25. Esposito K, Chiodini P, Capuano A, et al. Fracture risk and bone mineral density in metabolic syndrome: a meta-analysis. J Clin Endocrinol Metab 2013;98:3306-14.

26. You YS, Lin CY, Liang HJ, et al. Association between the metabolome and low bone mineral density in Taiwanese women determined by (1) H NMR spectroscopy. J Bone Miner Res 2014;29:212-22.

27. Yamaguchi T, Sugimoto T, Yano S, et al. Plasma lipids and osteoporosis in postmenopausal women. Endocr J 2002;49:211-7. 
Correction: Prevalence of and factors associated with adopting bone health promoting behaviours among people with osteoporosis in Taiwan: a cross-sectional study

Chen P, Lin M, Huang T, et al. Prevalence of and factors associated with adopting bone health promoting behaviours among people with osteoporosis in Taiwan: a crosssectional study. BMJ Open 2017;7:e015980. doi: 10.1136/bmjopen-2017-015980

The Funding statement should read:

Funding The study was supported by a grant from the Taiwan Formosa Plastic Company (FCRPF690011) and Chang Gung Memorial Hospital (BMRP148) as well as (CMRPGMF0012).

The Ethics approval statement should read:

Ethics approval This study was approved by the institutional review board of the ethical committee of Chang Gung Memorial Hospital (IRB 104-9925C).

Open Access This is an Open Access article distributed in accordance with the terms of the Creative Commons Attribution (CC BY 4.0) license, which permits others to distribute, remix, adapt and build upon this work, for commercial use, provided the original work is properly cited. See: http://creativecommons.org/licenses/by/4.0/

C Article author(s) (or their employer(s) unless otherwise stated in the text of the article) 2018. All rights reserved. No commercial use is permitted unless otherwise expressly granted.

BMJ Open 2018;8:e015980corr1. doi:10.1136/bmjopen-2017-015980corr1

A) Check for updates 